Research report

\title{
Slave to habit? Obesity is associated with decreased behavioural sensitivity to reward devaluation
}

\author{
Annette Horstmann a,b,c,*, Anja Dietrich ${ }^{\mathrm{b}}$, David Mathar ${ }^{\mathrm{a}, \mathrm{b}}$, Maria Pössel ${ }^{\mathrm{b}, \mathrm{c}}$, \\ Arno Villringer ${ }^{\mathrm{a}, \mathrm{b}, \mathrm{c}, \mathrm{d}, \mathrm{e}}$, Jane Neumann ${ }^{\mathrm{a}, \mathrm{b}, \mathrm{c}}$ \\ a Leipzig University Medical Center, IFB Adiposity Diseases, Philipp-Rosenthal-Straße 27, Leipzig, Germany \\ ${ }^{\mathrm{b}}$ Department of Neurology, MPI for Human Cognitive and Brain Sciences, Stephanstraße 1A, Leipzig 04103, Germany \\ ${ }^{\mathrm{c}}$ Leipzig University Medical Center, CRC 1052, Subprojects A1 E' A5, Leipzig, Germany \\ department of Cognitive Neurology, University Hospital Leipzig, Liebigstraße 16, Leipzig, Germany \\ e Mind E Brain Institute, Berlin School of Mind and Brain, Humboldt-University, Unter den Linden 6, Berlin, Germany
}

\section{A R T I C L E I N F O}

Article history:

Received 29 September 2014

Received in revised form 19 December

2014

Accepted 21 December 2014

Available online 24 December 2014

\section{Keywords:}

Obesity

Reward sensitivity

Goal-directed

Habitual

Devaluation

Control of food intake

\begin{abstract}
A B S T R A C T
The motivational value of food is lower during satiety compared to fasting. Dynamic changes in motivational value promote food seeking or meal cessation. In obesity this mechanism might be compromised since obese subjects ingest energy beyond homeostatic needs. Thus, lower adaptation of eating behaviour with respect to changes in motivational value might cause food overconsumption in obesity. To test this hypothesis, we implemented a selective satiation procedure to investigate the relationship between obesity and the size of the behavioural devaluation effect in humans. Lean to obese men (mean age 25.9, range 19-30 years; mean BMI 29.1, range $19.2-45.1 \mathrm{~kg} / \mathrm{m}^{2}$ ) were trained on a free operant paradigm and learned to associate cues with the possibility to win different food rewards by pressing a button. After the initial training phase, one of the rewards was devalued by consumption. Response rates for and wanting of the different rewards were measured pre and post devaluation. Behavioural sensitivity to reward devaluation, measured as the magnitude of difference between pre and post responses, was regressed against BMI. Results indicate that (1) higher BMI compared to lower BMI in men led to an attenuated behavioural adjustment to reward devaluation, and (2) the decrease in motivational value was associated with the decrease in response rate between pre and post. Change in explicitly reported motivational value, however, was not affected by BMI. Thus, we conclude that high BMI in men is associated with lower behavioural adaptation with respect to changes in motivational value of food, possibly resulting in automatic overeating patterns that are hard to control in daily life.
\end{abstract}

() 2014 Elsevier Ltd. All rights reserved.

\section{Introduction}

The motivational value of food scales with homeostatic state; that is, the incentive value of food is lower when subjects are sated compared to when they are fasted (Stoeckel, Cox, Cook, \& Weller, 2007).

\footnotetext{
Acknowledgments: We are grateful to Jonas Klinkenberg, Christina Lell and Ramona Menger for invaluable help during data collection for this study. The work of $\mathrm{AH}$, JN, and AV is supported by the IFB Adiposity Diseases, Federal Ministry of Education and Research (BMBF), Germany, FKZ: 01E01001 (http://www.bmbf.de). The work of $\mathrm{AH}, \mathrm{MP}, \mathrm{JN}$, and AV is funded by the German Research Foundation (DFG) (http://www.dfg.de), within the framework of the CRC 1052 'Obesity Mechanisms', projects A1 and A5. AD is funded by a research grant from the Konrad Adenauer Foundation (KAS), Germany (http://www.kas.de). DM is funded by a stipend from the FAZIT Foundation (http://www.fazit-stiftung.de).

Conflict of interest: The authors declare no conflict of interest. The funders had no role in study design, data collection and analysis, decision to publish, or preparation of the manuscript.

* Corresponding author.

E-mail address: horstmann@cbs.mpg.de (A. Horstmann).
}

Dynamic changes in motivational value are thought to contribute to the acute control of eating behaviour, e.g. promoting food seeking or cessation of a meal. In obesity, however, accurate adaptation of eating behaviour in response to acute changes in motivational value might be compromised. Obese subjects have been shown to ingest more energy than is required to meet their current homeostatic needs. Thus, disproportionate adaptation of eating behaviour with respect to changes in motivational value might be a possible cause of food overconsumption in obesity.

Effective adaptation of eating behaviour can only be achieved if action control is actually guided by the current motivational value of an actions' outcome. In general, action control can be described as being either predominantly habitual or goal-directed. According to the dual-system theory, flexible and effective behaviour is determined by the balance between goal-directed and habitual systems (Dickinson, 1985). Habitual and goal-directed action control systems are distinguishable by their varying degree of sensitivity to action outcomes, i.e. motivational value. Goal-directed behaviour is characterized by the actor's awareness of the action outcome and 
the ability to flexibly adapt behaviour to current needs and motivational states (Balleine \& Dickinson, 1998). The key feature of this system is its sensitivity to changes in motivational value. In contrast, habits are characterized by the actor's insensitivity to action outcomes; that is, the habitual action will be performed regardless of changes in motivational value of the outcome, triggered by action-associated cues. The balance between these action-control systems is influenced by external factors such as stress (Schwabe \& Wolf, 2011), personality traits such as impulsivity (e.g. Chase, 2011; Hogarth, 2012), neurologic and psychiatric disorders such as obsessive-compulsive disorder (Gillan et al., 2011), and addiction (Hogarth, Balleine, Corbit, \& Killcross, 2012), with the habitual system dominating in each case.

Here, we hypothesized that obesity is associated with a reduced behavioural sensitivity to changes in motivational value of an outcome, indicating habit-like behavioural control and, consequently, leading to overconsumption of food. A classic experimental paradigm to disentangle goal-directed and habitual behavioural control is the selective satiation procedure (Colwill \& Rescorla, 1985), which was initially developed for animal research (Murray \& Rudebeck, 2013). This procedure is frequently used to test the behavioural effects of manipulating the motivational value of rewards (e.g. Morewedge, Huh, \& Vosgerau, 2010). By allowing animals to consume one of two food rewards to satiety, the value of that food reward is decreased and animals subsequently show less motivation to perform actions that lead to the same food reward (Colwill \& Rescorla, 1985). This effect has since become known as a 'devaluation effect'. To test our hypothesis, we implemented a selective satiation procedure to investigate the relationship between obesity and the size of the devaluation effect in humans. Lean, overweight and obese subjects were trained on a free operant paradigm. Subjects learned to associate abstract stimuli with the possibility to win different snack food rewards by pressing a response button. After the initial training phase, one of the rewards was devalued by allowing ad libitum access. Subsequently, responses to the abstract stimuli indicating different food rewards were measured again. With successful devaluation provided, the magnitude of difference between responses for the devalued item before and after devaluation should vary positively with the degree of goal-directed action control. Consequently, habitual action control would be characterized by a low reduction in responses after devaluation.

\section{Materials and methods}

Subjects

30 male participants (mean age 25.93 years, range $19-30$ years; mean BMI $29.06 \mathrm{~kg} / \mathrm{m}^{2}$, range $19.20-45.06 \mathrm{~kg} / \mathrm{m}^{2}$ ) took part in the experiment. Subjects were screened via telephone calls prior to the experiment to explicitly exclude allergies against one of the snack food items a priori. Inclusion criteria were age between 18 and 35 years and BMI between 18.5 and $45 \mathrm{~kg} / \mathrm{m}^{2}$. Exclusion criteria were smoking, current use of medication, diabetes mellitus type I or II, or a history of neurological or psychiatric disorders. For each participant, written informed consent was obtained beforehand and the study was carried out in accordance with the Declaration of Helsinki. Since it has been proposed repeatedly that women are more prone than men to adjusting their food intake according to perceived social norms (e.g. Vartanian, Sokol, Herman, \& Polivy, 2013), we restricted our sample to men.

\section{Experimental paradigm and measures}

Before the experiment, subjects completed visual analogue scales (VAS), indicating their current level of hunger, satiety, and current wanting of two different sweet (M\&Ms, gummi bears) and two different savoury (peanuts, pretzels) snack items. Separate VAS were used to assess hunger and satiety since altered eating behaviour has been shown to decrease the linear relationship between these normally inverse measures (e.g. Halmi \& Sunday, 1991). For each subject, the most wanted sweet item and the most wanted savoury item were chosen for the subsequent devaluation experiment, and devaluation was performed using the higher-rated of the two, regardless of taste quality to ensure a high initial response rate. Presentation of stimuli and recording of button presses was implemented using Presentation 14.1 (Neurobehavioral Systems Inc., Albany, CA, USA).

\section{Exclusion criteria}

In order to ensure a successful implicit devaluation we excluded some subjects from data analysis. Firstly, we precluded one subject who did not currently want any of the possible devalued foods (VAS scale of wanting the devalued item $=0$ ). Secondly, one subject who ate too much of the devalued food to resemble snacking behaviour (cut-off $881 \mathrm{kcal}$, which is more than the 95th percentile of the distribution and represents about $40 \%$ of the recommended total daily calorie intake) was excluded. Of the remaining subjects, only $n=2$ rated their favourite savoury item higher than the sweet one and, accordingly, were devalued using a savoury snack item. In order to avoid any biasing effect of taste quality due to this misbalance, we furthermore restricted our analysis to those subjects for whom sweet snack items were devaluated. In total, data obtained from $n=26$ subjects entered statistical analysis.

The experiment consisted of three phases:

\section{Training.}

In an initial training phase, subjects learned the association between two abstract stimuli (fractal images, see Fig. 1), their response rate of a button press, and the possibility to win one of two possible rewards (sweet and savoury item). The training phase was separated into 10 blocks, consisting of five blocks for each sweet and savoury food reward in a randomized order and five breaks of $20 \mathrm{~s}$ in between. Each block lasted between 20 and $40 \mathrm{~s}$ (uniformly distributed, not apparent to the participant). Within these timespans, each $n$th button press, matching an $a$ priori generated, uniformly distributed number $n$ within the interval [15 20], was rewarded and subjects got visual feedback about their won reward for one second. Thus, a high response rate increased the possibility to win a high quantity of food rewards. After non-rewarded button-presses, subjects received a short neutral feedback (grey dot) for $50 \mathrm{~ms}$. Response rate in button clicks per second was recorded for each of the ten consecutive blocks of the training phase. The association between fractal images and type of reward was counterbalanced between subjects. Subjects received the total rewards won at the end of the first phase and were instructed beforehand to consume all of them immediately.

2. Implicit devaluation.

Subjects were told that there was a short break in the experiment and they were given ad libitum access to a huge quantity of one of the rewards. They were told that these snacks were leftovers from a celebration in the department that day and that they may feel free to help themselves to as much of it as they liked. Subjects watched a film (nature documentary) for 30 minutes and subsequently answered a short (fake) questionnaire about its content. The amount consumed from the reward was quantified in grams without subjects' notice, and energy consumed during the break was calculated in kilocalories (kcal).

3. Devaluation test.

After implicit devaluation, subjects again completed the VAS regarding their current feelings of hunger, satiety and their momentary wanting of the non-devalued as well as the devalued 


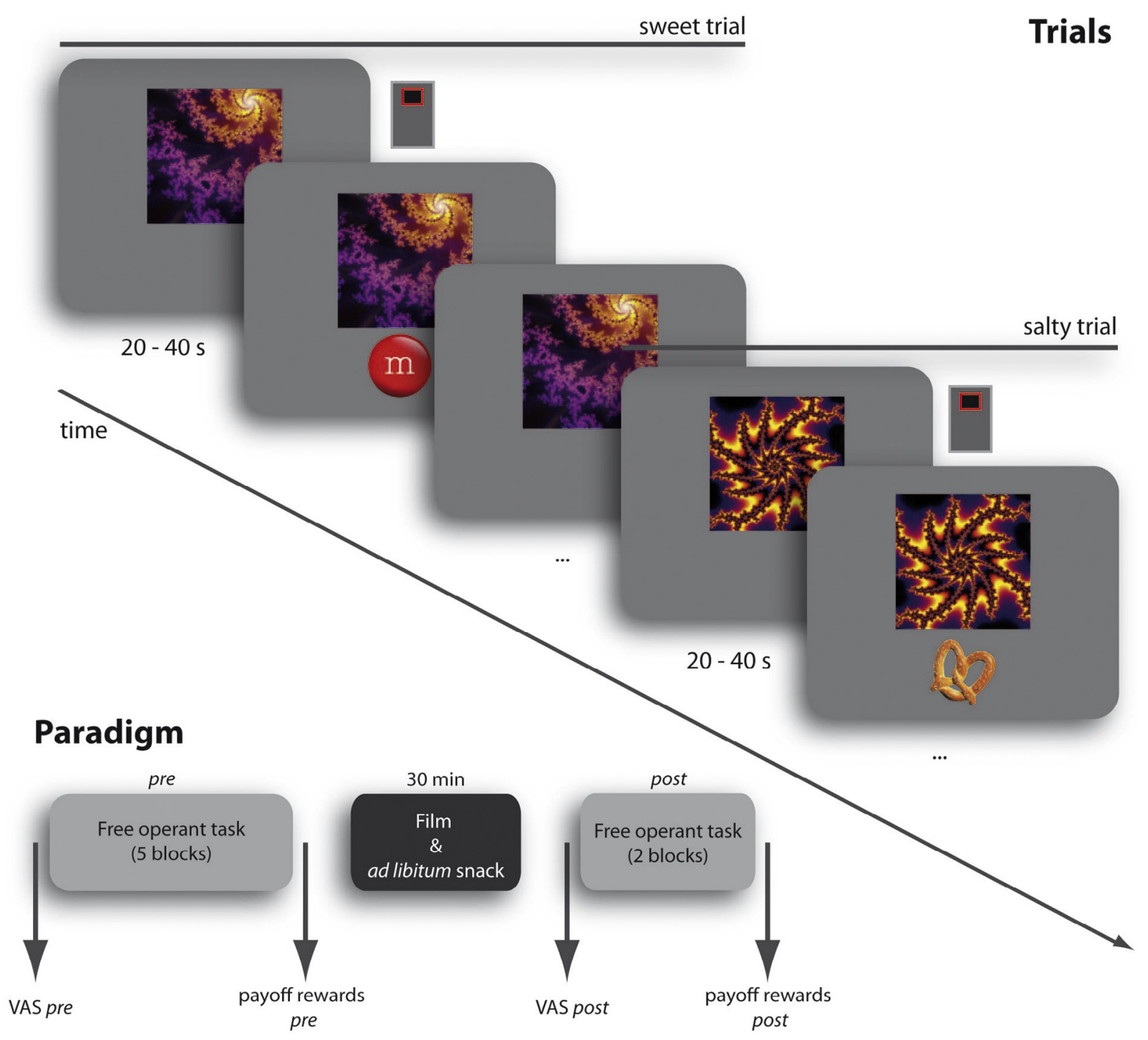

Fig. 1. Trial structure (top) and general experimental paradigm (bottom).

item. Subsequently, response rate to both abstract stimuli was measured again during four consecutive blocks, consisting of two blocks for each reward type in a randomized order with a short break (20 s) in between.

For the calculation of total energy consumed before the test phase, kcals from won items of the training phase were added to the kcals consumed in the devaluation phase.

\section{Questionnaires}

We assessed the presence of eating disorders with the help of the Eating Disorder Inventory 2 (Garner, 1991) in order to exclude subjects exhibiting Bulimia Nervosa, Anorexia Nervosa or Binge Eating Disorder. No subjects were excluded because of the presence of eating disorders. To exclude possible confounding effects of depressive symptoms, which may in itself influence drive and motoric vigour, we administered the German version of Beck's Depression Inventory (Beck, Ward, Mendelson, Mock, \& Erbaugh, 1961) with a cut-off value of 18 . No subjects had to be excluded because of this criterion.

\section{Statistical analyses}

Data were analysed using SPSS software (IBM SPSS Statistics 19.0). Prior to statistical analysis, normality of all data sets was assessed by Kolmogorov-Smirnov tests with no significant results. Therefore, normal distribution can be assumed for all tested variables.

\section{General efficacy of devaluation procedure}

To examine the general efficacy of our devaluation procedure, repeated measures ANOVAs were computed on explicit wanting and response rate, using time (pre, post) and reward (devalued, not devalued) as within subject factors, modelling main effects as well as the interaction between both factors. Because we were interested in response rate after initial learning of the contingencies of the task (blocks 1 and 2, see Fig. 2), we averaged the response rate of blocks three to five to represent response rate prior to devaluation (presession) and took the average of the two test blocks to represent response rate after devaluation (post-session). Subsequently, planned paired t-tests were used to examine devaluation effects within each reward category separately. 


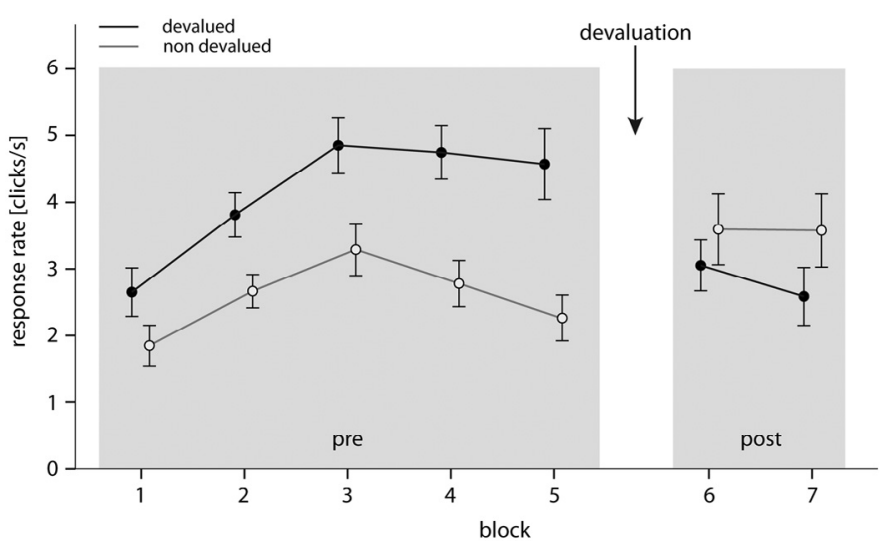

Fig. 2. Evolution of response rates for devalued and not devalued rewards before and after devaluation. Error bars indicate standard error of the mean (SEM); filled circles $=$ responses to devalued reward cue, open circles $=$ responses to non devalued reward cue.

\section{The effect of weight status on devaluation}

To examine the influence of weight status on reward devaluation we applied a multiple linear regression analysis. Change in response rate for the devalued item from pre to post devaluation was the dependent variable and BMI served as predictor variable. Further, we included change in motivational value (i.e. percentage change in current wanting from pre to post) of the devalued item between pre and post devaluation. In addition, the model was corrected for individual baseline levels of subjective hunger/satiety ratings, presumably reflecting current homeostatic state. Specifically, to avoid influences of multi-collinearity, ratings of satiety prior to the experiment were standardized to the reported levels of initial hunger and both variables were entered in the analysis.

All statistical evaluations were performed at an alpha level of .05 .

\section{Results}

Participant characteristics regarding age and BMI, along with initial ratings of subjective hunger/satiety prior to devaluation, wanting of devalued item prior to and after devaluation, number of sweet and savoury items won during training, and calories ingested during devaluation are given in Table 1.

There was no significant linear association between total energy intake during the experiment and BMI, reported initial hunger or satiety, or reported initial wanting of the devaluated reward

Table 1

Participant characteristics.

\begin{tabular}{lc}
\hline Male $(n=23)$ & Mean (SD) \\
\hline Age & $25.8(4.1)$ \\
BMI & $28.7(6.72)$ \\
Hungry rating pre [mm VAS] & $27.50(20.94)$ \\
Sated rating pre [mm VAS] & $61.73(25.74)$ \\
Wanting devalued item pre [mm VAS] & $47.12(26.46)$ \\
Wanting devalued item post [mm VAS] & $18.77(17.99)$ \\
Won devalued reward (sweet) [\#items] - training session & $17.88(6.64)$ \\
Won non-devalued reward (savoury) [\#items] - training & $9.50(4.84)$ \\
$\quad$ session & $311.09(223.6)$ \\
Energy consumed from devalued reward [kcals] - training & \\
$\quad$ session + implicit devaluation & \\
\hline
\end{tabular}

$\mathrm{SD}$, standard deviation. (all $\mathrm{r} \leq .318, P$-values $\geq .113$ ). However, there was a moderate positive correlation at trend level between initially reported wanting and subsequent consumption of the devalued reward $(r=.317$, $P=.115$ ). This indicates that total energy intake may depend on reported initial wanting of the reward, therefore supporting the assumption of ecological validity of the reported VAS values.

Participants learned the association between predictive stimuli, response rate and reward delivery after the two initial blocks of training, as can be derived from Fig. 2, where for both items response rates quickly rise to a maximum after the first two blocks.

First, we investigated the general efficacy of the devaluation procedure on subjectively reported motivational value, i.e. wanting, in the whole sample. A repeated measures ANOVA with the factors time (pre, post devaluation) and reward category (devalued, nondevalued) indicated a significant interaction between time and reward category $\left(F_{1,25}=9.09, P=.004\right)$ and a main effect of time on explicit wanting $\left(F_{1,25}=40.46, P<.001\right)$. Next, we analysed specifically whether individual wanting of the devalued item differed between pre and post devaluation. There was a significant difference, with lower values following devaluation (pre devaluation: mean $=47.12 \mathrm{~mm}$ VAS, $\mathrm{SD}=26.46$; post devaluation: mean $=18.77 \mathrm{~mm}$ VAS, $\mathrm{SD}=17.99$; paired t-test, $\mathrm{T}=6.29, P<.001$, Fig. $3 \mathrm{~A}$ ). BMI did not significantly influence the change in individual wanting of either reward type (separate repeated measures ANCOVAS with factor time and BMI as covariate, both $P$-values $>.38$ ).

Further, we investigated whether the amount of calories consumed during devaluation significantly influenced the change in reported subjective wanting of the devalued reward before and after devaluation. There was a trend for a direct relationship $(r=-.39$, $P=.052$ ). This did not change when controlling for participants' BMI via partial correlation $(\mathrm{r}=-.384, P=.058)$; there was still a trendlevel negative linear association between the amount of calories consumed during devaluation and the corresponding change in reported wanting, i.e. the more subjects ate during devaluation, the less they explicitly wanted the reward after devaluation.

Second, we analysed whether response rate to the abstract stimulus associated with the devaluated reward dropped in the whole group after devaluation.

Because we were interested in response rate after initial learning of the contingencies of the task, we averaged response rate of blocks three to five to represent response rate prior to devaluation and took the average of the two test blocks to represent response rate after devaluation for the subsequent analysis. A repeated measures ANOVA with within-subject factors time (pre/post) and reward type (devalued/not devalued) showed no significant main effects of either time $\left(\mathrm{F}_{1,25}=2.41, P=.133\right)$ or reward $\left(\mathrm{F}_{1,25}=3.18, P=.087\right)$ on response rate, but a significant interaction of factors time and reward $\left(F_{1,25}=9.45, P=.005\right)$. Following up on this interaction effect, we performed paired samples t-tests within each condition separately. As expected, there was a decrease in response rate for the devalued food item after devaluation in the whole sample (pre devaluation: mean $=4.72$ clicks $/ \mathrm{s}, \mathrm{SD}=1.99$; post devaluation: mean $=2.82$ clicks $/ \mathrm{s}, \mathrm{SD}=1.97$; T-value $=3.11, P=.005)$, but not for the not devalued reward (pre devaluation: mean $=2.78 \mathrm{clicks} / \mathrm{s}$, $\mathrm{SD}=1.44$; post devaluation: mean $=3.59$ clicks $/ \mathrm{s}, \mathrm{SD}=2.70$; n.s., Fig. 3B).

Based on our hypothesis we expected an attenuating effect of weight status on the strength of the behavioural devaluation effect. Accordingly, subjects with higher BMI should show a continuing response after devaluation. To examine the link between the strength of devaluation effect and BMI, we applied a multiple linear regression analysis, controlling for initial subjective hunger/satiety ratings and change in wanting of the devalued food item (see Table 1). In Table 2 the statistical association between these variables is given. The model explains $46 \%$ of the total variance in behaviour $\left(\mathrm{F}_{(3,25)}=6.28, P=.003\right)$. 

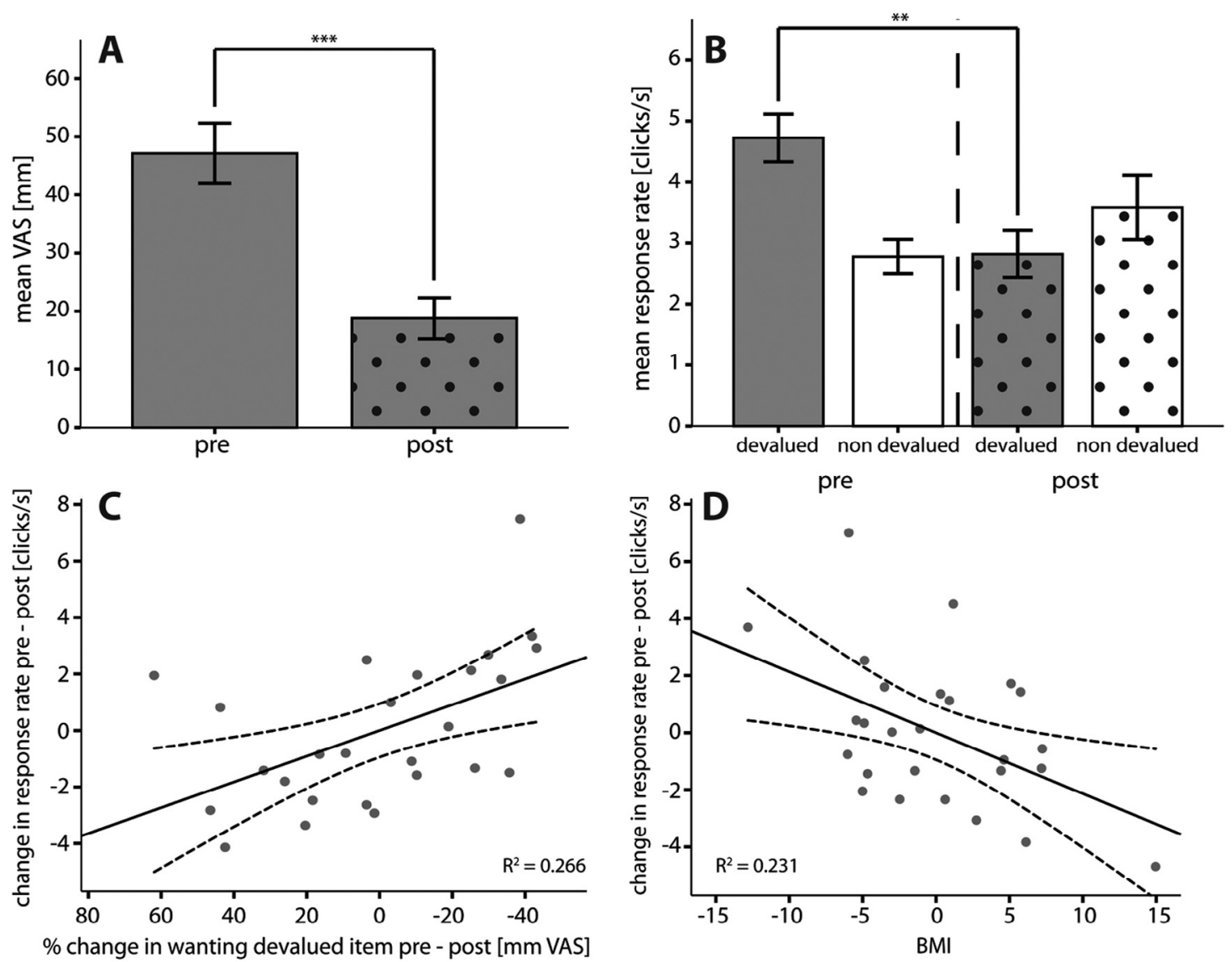

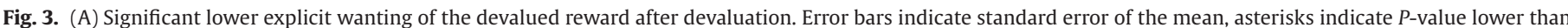

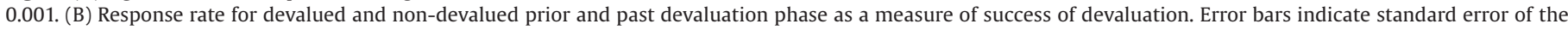

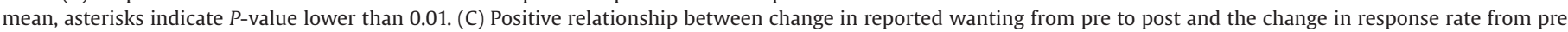

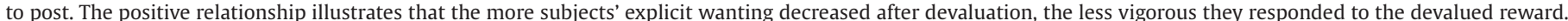

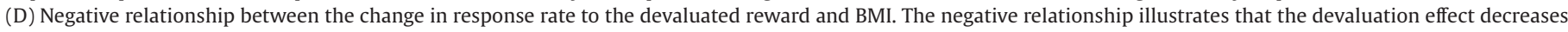

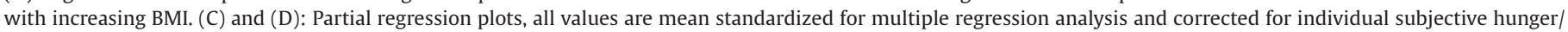
satiety ratings.

The explicitly reported change in wanting the devalued reward had a significant effect on the magnitude of change in response rate, i.e. the higher the reported decrease in explicit wanting, the higher the decrease in response rate between pre and post (Fig. 3C). Interestingly, BMI had an inverse relationship with decrease in response rate: Higher BMI compared to lower BMI in men led to an attenuated behavioural adjustment to reward devaluation; that is, the difference in response rate before and after devaluation was significantly reduced with increasing BMI (Fig. 3D). Additionally, the induced devaluation effect was found to be greater in subjects reporting higher levels of satiety upon arrival in the lab.

Table 2

Effects of Body Mass Index (BMI), and decrease in motivational value of the devalued food item on the decrease of response rates pre and post devaluation, adjusted for subjects' subjective hunger/satiety rating. Additionally, the influence of initial hunger/satiety rating on the devaluation effect is given.

\begin{tabular}{llcc}
\hline Variable & $\begin{array}{l}\text { Coefficient } \\
\text { (standardized) }\end{array}$ & $t$-Value & $P$-value \\
\hline BMI & -0.459 & -2.57 & 0.017 \\
$\begin{array}{l}\text { Decrease in wanting devalued } \\
\text { item [diff mm VAS] }\end{array}$ & 0.449 & 2.83 & 0.010 \\
Initial hunger/satiety rating & 0.75 & 3.60 & 0.002 \\
\hline
\end{tabular}

\section{Discussion}

\section{Summary}

The current study aimed at examining differences in foodrelated goal-directed vs. habitual action control associated with weight status. For this purpose a classical devaluation experiment was conducted. First of all we could show that the devaluation procedure was generally successful as explicit wanting ratings and responding for the devalued snack food dropped after the devaluation phase. The change of explicit wanting from pre to post devaluation affected devaluation success, thus emphasizing the role of motivation in goal-directed behaviour. Most importantly, we found a negative relationship between subjects' weight status (i.e. BMI) and the devaluation effect. In accordance with our hypothesis subjects with a high BMI showed an attenuated reduction of responses after the devaluation phase. This indicates lower adaptation to changes in motivational value and corresponding dominance of habit-like behaviour in obesity.

\section{Body weight status and action control}

From previous research on sensory-specific satiety it is known that repeated exposure to a certain kind of food leads to a temporary 
decline in pleasure derived from consuming that particular food (Havermans, Janssen, Giesen, Roefs, \& Jansen, 2009; Rolls, Rolls, Rowe, \& Sweeney, 1981; Snoek, Huntjens, Van Gemert, De Graaf, \& Weenen, 2004). Further, repeated exposure also leads to corresponding behavioural adaptation, i.e. a decrease in responding for that food due to habituation (reviewed by Epstein, Temple, Roemmich, \& Bouton, 2009). It has previously been reported that this behavioural adaptation is slowed down in obesity (Carr \& Epstein, 2011; Epstein, Robinson, Roemmich, \& Marusewski, 2011). Extending these findings, we showed that induced changes in motivational value after repeated food exposure are not appropriately translated into behaviour in subjects with higher BMI. Further, our study adds the aspect of stimulus-associated responding to the existing literature, allowing interpretation of behaviour in the light of goaldirected vs. habitual action control.

According to the dual-system theory, there are two mechanisms underlying learning and action control (Dickinson, 1985). We assume these mechanisms to account for the observed BMIrelated effect on devaluation sensitivity. One mechanism encodes the relationship between actions or responses and their consequences or outcomes (R-O associations), leading to goal-directed behavioural control. A second mechanism is based on the formation of stimulus-response (S-R) associations. These associations are established in proportion to the contingent co-occurrence of the S-R pairs before reinforcement through the outcome. With repetition this leads to stimulus-triggered habitual behavioural control that is independent of outcome retrieval (see Balleine \& O'Doherty, 2010, for a review). In general, goal-directed and habitual mechanisms are supposed to be in balance, with one of them predominating according to the particular need, making behaviour flexible (via goaldirected control) and effective (via habitual control) (Dickinson, 1985). Our data support the hypothesis that action control might be shifted towards habitual control in obesity, rendering these two systems unbalanced. Based on the reported relationship between BMI and behavioural devaluation sensitivity we assume dominance of habitlike responding to be a feature of obesity. In accordance with previous studies we presume that there are individuals more sensitive to the rewarding properties of food (Davis \& Fox, 2008; Davis, Strachan, \& Berkson, 2004; Davis et al., 2007; Franken \& Muris, 2005), who regularly overeat on palatable (rewarding) food. A long history of regular excess eating presumably leads to strengthening of S-R, i.e. food cue/ consumption associations. As a result eating might change progressively into an automatic or habitual process that is triggered by food stimuli and characterized by reduced sensitivity to changes in motivational value. Unfortunately, we do not have quantitative data on the history of overeating behaviour of our subjects to test this relationship directly in our sample.

Further, in humans, excess weight is related to heightened craving, i.e. the intense desire or urge to eat a specific food (Weingarten \& Elston, 1990). Craving-inducing cues are perceived as attractive; they automatically capture attention and trigger appetitive responses that guide behaviour towards target acquisition and consumption. This is called approach bias (Robinson \& Berridge, 1993). Interestingly, overweight and obese individuals show an enhanced food approach bias (Havermans, Giesen, Houben, \& Jansen, 2011), which is in line with the idea of heightened automatic or habit-like responding for (desired) foods as observed in the current study.

\section{Explicit wanting and action control}

The positive relationship between change in wanting from pre to post and change in response rate from pre to post indicated that devaluation success was indeed associated with a change in motivation in the present experimental setup. In other words, if there was selective satiation for the devalued item (= low post motivation in comparison to pre motivation), this also translated into behavioural devaluation, thus validating the behavioural paradigm. Motivational value has previously been shown to be an appropriate predictor of food intake in normal-weight subjects: the motivational value (as assessed by explicit wanting) was a better predictor of energy intake than the hedonic value (as assessed by explicit liking) in a non-obese sample (Epstein et al., 2004).

\section{From habits to compulsivity}

The current study is to our knowledge the first to investigate the relationship between human body weight status and habitual responding by means of a devaluation experiment. Habitual responding, as observed in the present study, might share characteristics with compulsive behaviour as observed in drug dependence. Typical compulsive actions are mainly cue-triggered. Drug dependency is characterized by such cue-triggered actions (Everitt et al., 2008; Everitt \& Robbins, 2005). In obesity, heightened sensitivity to food cues on the behavioural and neural level has been demonstrated repeatedly, indicating higher incentive salience of these cues (e.g. Castellanos et al., 2009; Nijs \& Franken, 2012; Nummenmaa et al., 2012). Therefore, overeating patterns in obesity might resemble cue-triggered behavioural patterns of drugseeking and -taking (Everitt \& Robbins, 2005; Volkow, Wang, Tomasi, \& Baler, 2013). Previous investigations explored aspects of decisionmaking behaviour in obesity that may be associated with the gradual development of habits. These investigations demonstrated heightened unpremeditated decision making in obese in contrast to lean individuals (Delay Discounting Task: Rasmussen, Lawyer, \& Reilly, 2010; Weller, Cook, Avsar, \& Cox, 2008; Weygandt et al., 2013; Stop Signal Task: Nederkoorn, Braet, Van Eijs, Tanghe, \& Jansen, 2006; Nederkoorn, Smulders, Havermans, Roefs, \& Jansen, 2006; Iowa Gambling Task: Brogan, Hevey, O'Callaghan, Yoder, \& O'Shea, 2011; Horstmann et al., 2011; Pignatti et al., 2006; Go/NoGo Task: Batterink, Yokum, \& Stice, 2010). Impaired goal-directed control and dominant habit learning have also been associated with trait impulsivity (Hogarth, Chase, \& Baess, 2012) in the context of addiction, rendering vulnerable individuals more prone to developing dependency and, consequently, exhibiting compulsive behaviour (Belin, Mar, Dalley, Robbins, \& Everitt, 2008; Everitt et al., 2008; Verdejo-García, Lawrence, \& Clark, 2008). In rodent studies, it has been demonstrated that drug-naïve high impulsive individuals are more likely to engage in drug self-administration than their low impulsive littermates (Dalley et al., 2007). Interestingly, drug dependency shares several similarities with obesity (García-García et al., 2014; see Volkow et al., 2013, for a review). Thus, a tendency to unpremeditated behaviour might also be a precursor of the transition from goal-directed (reward-driven) to habit-like (stimulus-driven) food consumption. Habitual responding, i.e. behavioural control which is not closely adjusted to current motivational value, may have consequences for both meal initiation and meal termination. In the former case, food intake is initiated without current wanting (i.e. closely related to eating in the absence of hunger); in the latter, a meal is not terminated although the motivational value has already decreased.

\section{Neurobiological basis}

The dopaminergic system is prominently involved in reward processing and conditioning of reward-associated stimuli. DA release into the mesolimbic pathway mediates the powerful reinforcing effects of both drugs and food (Small, Jones-Gotman, \& Dagher, 2003; Volkow, Wang, Fowler, \& Telang, 2008; Volkow et al., 2013). Moreover, DA is also released post-prandially, possibly mediating the successive devaluation of food reward during a meal (de Auraujo et al. Neuron 2008) in addition to its release during anticipation and acute consumption of food rewards. Excessive eating, similar to 
chronic drug consumption, progressively leads to alterations in the dopaminergic system, specifically to a down-regulation of striatal dopamine 2 and/or 3 (D2/D3) receptors (De Weijer et al., 2011; Eisenstein et al., 2013; Geiger et al., 2009; Nader et al., 2006; Thanos, Michaelides, Benveniste, Wang, \& Volkow, 2007; Wang et al., 2001). This down-regulation, among other factors, is assumed to induce a shift to cue-triggered habit-like consumption (Volkow et al., 2013). Indeed, a recent human PET study reported opposing relationships between striatal $\mathrm{D}_{2}$-receptor binding potential and opportunistic eating behaviour in ventromedial (negative relationship) and dorsolateral (positive relationship) striatum in obese subjects (Guo, Simmons, Herscovitch, Martin, \& Hall, 2014).

On the level of brain structures, the shift from voluntary drug use to compulsive drug-seeking represents a transition from prefrontal cortical to striatal control over drug intake, as well as a switch from ventral (particularly Nc. accumbens) to more dorsal (putamen) domains of the striatum. This shift may at least in part be mediated by the aforementioned gradual changes in dopamine signalling (DA) (Everitt et al., 2008; Everitt \& Robbins, 2005; Volkow et al., 2013). With respect to obesity, there are now several studies showing structural as well as functional differences in prefrontal and striatal regions. These differences have been previously associated with variations in reward anticipation and reward processing, as well as behavioural flexibility (e.g. Horstmann et al., 2011; Killgore \& Yurgelun-Todd, 2005; Le et al., 2006; Pannacciulli et al., 2006; Rothemund et al., 2007; Stoeckel et al., 2008). Future studies should investigate whether such neuronal alterations are linked to behavioural differences regarding the balance between habitual vs. goal-directed action control in obesity.

\section{Limitations}

Due to the finding that women are more likely to adjust food intake according to perceived social norms (e.g. Vartanian et al., 2013), the current study was restricted to males. Therefore, our findings are for now limited to males. Nevertheless, similar mechanisms are expected for women. Upcoming studies should thus especially address this question in women. Additionally, we decided in favour of an implicit devaluation approach as it seemed to be the most natural setting, and subjects were more likely to stay unaware of the fact that the devaluation was part of the experiment. Thus, subjects were not explicitly told to eat one of the food items until it is no longer pleasant to them, but could eat ad libitum from the snack to achieve reward-specific devaluation while watching a film. Accordingly, the amount people ate from the reward during devaluation varied between subjects. Future approaches might ensure that subjects ingest a minimum amount of the reward. Further, devaluation efficacy might have been influenced by participants' individual beliefs and expectations about the snack, as well as their eating customs, and the ability to monitor food intake (Higgs, 2008; reviewed by Wansink, 2004). Decisions about food intake, for example, depend on memory of previous food consumption, with the hippocampus playing a crucial role in this context by inhibiting further appetitive responses (Higgs, 2008). Thus, watching the nature documentary in our study might have compromised participants' ability to monitor and memorize food intake by distracting from satiety signals (Bellissimo, Pencharz, Thomas, \& Anderson, 2007; Hetherington, Anderson, Norton, \& Newson, 2006; Higgs \& Woodward, 2009; Temple, Giacomelli, Kent, Roemmich, \& Epstein, 2007), leading to decreased devaluation efficacy. Distraction by watching TV could have potentially affected obese participants in particular (Ekelund et al., 2006). Future studies could adapt the procedure in order to avoid potential effects of distractors. Moreover, there was a general preference for the sweet snack across participants. Only few volunteers preferred savoury to sweet snacks and received corresponding devaluation. We initially planned to counterbalance devalued taste qualities between subjects, but for motivational reasons (subjects will respond more for a more wanted snack), we decided to devalue the most wanted snack item. Future studies could screen subjects beforehand to balance the taste quality conditions. Finally, to reduce influences of initial subjective hunger/ satiety, it may be advisable in the future to provide a standard breakfast or meal for all subjects before the experiment to ensure a more homogeneous level of hunger and satiety.

\section{Conclusions}

To our knowledge, this is the first study that reports differences in food-related goal-directed vs. habitual action control dependent on weight status using a classical devaluation task. We demonstrated that high BMI was associated with heightened habit-like responding for a snack food, i.e. lower adaptation of eating behaviour with respect to changes in motivational value. Importantly, explicitly reported change in motivational value was not affected by BMI.

Regarding daily life, the results of the current study indicate that food intake of particularly overweight and obese men is stimulated by food cues, probably leading to phenomena like eating in the absence of hunger or late meal cessation. Consequently, cueinduced eating may explain an aspect of overweight and obese individuals' difficulties in properly regulating their caloric intake and avoidance of energy overload. Considering that, behavioural sensitivity to devaluation seems to be a useful measure to characterize people's susceptibility to cue-induced overeating.

\section{References}

Balleine, B. W., \& Dickinson, A. (1998). Goal-directed instrumental action. Contingency and incentive learning and their cortical substrates. Neuropharmacology, 37(4-5), 407-419.

Balleine, B. W., \& O'Doherty, J. P. (2010). Human and rodent homologies in action control. Corticostriatal determinants of goal-directed and habitual action. Neuropsychopharmacology: Official Publication of the American College of Neuropsychopharmacology, 35(1), 48-69. doi:10.1038/npp.2009.131.

Batterink, L., Yokum, S., \& Stice, E. (2010). Body mass correlates inversely with inhibitory control in response to food among adolescent girls. An fMRI study. Neuroimage, 52(4), 1696-1703. doi:10.1016/j.neuroimage.2010.05.059.

Beck, A. T., Ward, C. H., Mendelson, M., Mock, J., \& Erbaugh, J. (1961). An inventory for measuring depression. Archives of General Psychiatry, 4, 561-571.

Belin, D., Mar, A. C., Dalley, J. W., Robbins, T. W., \& Everitt, B. J. (2008). High impulsivity predicts the switch to compulsive cocaine-taking. Science (New York, N.Y.), 320(5881), 1352-1355. doi:10.1126/science.1158136.

Bellissimo, N., Pencharz, P. B., Thomas, S. G., \& Anderson, G. H. (2007). Effect of television viewing at mealtime on food intake after a glucose preload in boys. Pediatric Research, 61(6), 745-749. doi:10.1203/pdr.0b013e3180536591.

Brogan, A., Hevey, D., O’Callaghan, G., Yoder, R., \& O'Shea, D. (2011). Impaired decision making among morbidly obese adults. Journal of Psychosomatic Research, 70(2), 189-196. doi:10.1016/j.jpsychores.2010.07.012.

Carr, K. A., \& Epstein, L. H. (2011). Relationship between food habituation and reinforcing efficacy of food. Learning and Motivation, 42(2), 165-172. doi:10.1016 /j.Imot.2011.01.003.

Castellanos, E. H., Charboneau, E., Dietrich, M. S., Park, S., Bradley, B. P., Mogg, K. et al. (2009). Obese adults have visual attention bias for food cue images. Evidence for altered reward system function. International Journal of Obesity (2005), 33(9), 1063-1073. doi:10.1038/ijo.2009.138.

Chase, H. W., \& Hogarth, L. (2011). Impulsivity and symptoms of nicotine dependence in a young adult population. Nicotine and Tobacco Research, 13, 1321-1325.

Colwill, R. M., \& Rescorla, R. A. (1985). Postconditioning devaluation of a reinforcer affects instrumental responding. Journal of Experimental Psychology. Animal Behavior Processes, 11(1), 120-132. doi:10.1037//0097-7403.11.1.120.

Dalley, J., Fryer, T., Brichard, L., Robinson, E. S., Theobald, D. E., Lääne, K., et al. (2007). Nucleus accumbens D2/3 receptors predict trait impulsivity and cocaine reinforcement. Science, 315, 1267-1270.

Davis, C., \& Fox, J. (2008). Sensitivity to reward and body mass index (BMI). Evidence for a non-linear relationship. Appetite, 50(1), 43-49. doi:10.1016/ j.appet.2007.05.007.

Davis, C., Patte, K., Levitan, R., Reid, C., Tweed, S., \& Curtis, C. (2007). From motivation to behaviour. A model of reward sensitivity, overeating, and food preferences in the risk profile for obesity. Appetite, 48(1), 12-19. doi:10.1016/ j.appet.2006.05.016 
Davis, C., Strachan, S., \& Berkson, M. (2004). Sensitivity to reward. Implications for overeating and overweight. Appetite, 42(2), 131-138. doi:10.1016/ j.appet.2003.07.004.

de Araujo, I. E., Oliveira-Maia, A. J., Sotnikova, T. D., Gainetdinov, R. R., Caron, M. G., Nicolelis, M. A., et al. (2008). Food reward in the absence of taste receptor signaling. Neuron, 57, 930-941.

De Weijer, B. A., van de Giessen, E., van Amelsvoort, T. A., Boot, E., Braak, B., Janssen, I. M., et al. (2011). Lower striatal dopamine D2/3 receptor availability in obese compared with non-obese subjects. EJNMMI Research, 1(1), 37. doi:10.1186/2191219X-1-37.

Dickinson, A. (1985). Actions and habits. The development of behavioural autonomy. Philosophical Transactions of the Royal Society of London. Series B, Biological Sciences, 308(1135), 67-78.

Eisenstein, S. A., Antenor-Dorsey, J. A. V., Gredysa, D. M., Koller, J. M., Bihun, E. C., Ranck, S. A., et al. (2013). A comparison of D2 receptor specific binding in obese and normal-weight individuals using PET with $(\mathrm{N}-[(11) \mathrm{C}]$ methyl)benperidol. Synapse (New York, N.Y.), 67(11), 748-756. doi:10.1002/syn.21680.

Ekelund, U., Brage, S., Froberg, K., Harro, M., Anderssen, S. A., Sardinha, L. B., et al. (2006). TV viewing and physical activity are independently associated with metabolic risk in children. The European Youth Heart Study. PLoS Medicine, 3(12), e488. doi:10.1371/journal.pmed.0030488.

Epstein, L. H., Robinson, J. L., Roemmich, J. N., \& Marusewski, A. (2011). Slow rates of habituation predict greater zBMI gains over 12 months in lean children. Eating Behaviors, 12(3), 214-218. doi:10.1016/j.eatbeh.2011.05.001.

Epstein, L. H., Temple, J. L., Roemmich, J. N., \& Bouton, M. E. (2009). Habituation as a determinant of human food intake. Psychological Review, 116(2), 384-407. doi:10.1037/a0015074.Habituation.

Epstein, L. H., Wright, S. M., Paluch, R. A., Leddy, J., Hawk, L. W., Jaroni, J. L., et al. (2004). Food hedonics and reinforcement as determinants of laboratory food intake in smokers. Physiology \& Behavior, 81(3), 511-517. doi:10.1016/ j.physbeh.2004.02.015.

Everitt, B. J., Belin, D., Economidou, D., Pelloux, Y., Dalley, J. W., \& Robbins, T. W. (2008). Review. Neural mechanisms underlying the vulnerability to develop compulsive drug-seeking habits and addiction. Philosophical Transactions of the Royal Society of London. Series B, Biological Sciences, 363(1507), 3125-3135. doi:10.1098/rstb.2008.0089.

Everitt, B. J., \& Robbins, T. W. (2005). Neural systems of reinforcement for drug addiction. From actions to habits to compulsion. Nature Neuroscience, 8(11), 1481-1489. doi:10.1038/nn1579.

Franken, I. H., \& Muris, P. (2005). Individual differences in reward sensitivity are related to food craving and relative body weight in healthy women. Appetite, 45(2), 198-201. doi:10.1016/j.appet.2005.04.004.

García-García, I., Horstmann, A., Jurado, M. A., Garolera, M., Chaudhry, S. J., Margulies, D. S., et al. (2014). Reward processing in obesity, substance addiction and non-substance addiction. Obesity Reviews: An Official Journal of the International Association for the Study of Obesity, doi:10.1111/obr.12221.

Garner, D. M. (1991). EDI-2. Eating disorder inventory-2. Professional manual.

Geiger, B. M., Haburcak, M., Avena, N. M., Moyer, M. C., Hoebel, B. G., \& Pothos, E. N. (2009). Deficits of mesolimbic dopamine neurotransmission in rat dietary obesity. Neuroscience, 159(4), 1193-1199. doi:10.1016/j.neuroscience.2009.02.007.

Gillan, C. M., Papmeyer, M., Morein-Zamir, S., Sahakian, B. J., Fineberg, N. A., Robbins, T. W., et al. (2011). Disruption in the balance between goal-directed behavior and habit learning in obsessive-compulsive disorder. The American Journal of Psychiatry, 168(7), 718-726. doi:10.1176/appi.ajp.2011.10071062.

Guo, J., Simmons, W. K., Herscovitch, P., Martin, A., \& Hall, K. D. (2014). Striatal dopamine D2-like receptor correlation patterns with human obesity and opportunistic eating behavior. Molecular Psychiatry, 19(10), 1078-1084. doi:10.1038/mp.2014.102.

Halmi, K. A., \& Sunday, S. R. (1991). Temporal patterns of hunger and fullness ratings and related cognitions in anorexia and bulimia. Appetite, 16(3), 219-237.

Havermans, R. C., Giesen, J. C. A. H., Houben, K., \& Jansen, A. (2011). Weight, gender, and snack appeal. Eating Behaviors, 12(2), 126-130. doi:10.1016/ j.eatbeh.2011.01.010

Havermans, R. C., Janssen, T., Giesen, J. C. A. H., Roefs, A., \& Jansen, A. (2009). Food liking, food wanting, and sensory-specific satiety. Appetite, 52(1), 222-225. doi:10.1016/j.appet.2008.09.020.

Hetherington, M. M., Anderson, A. S., Norton, G. N. M., \& Newson, L. (2006). Situational effects on meal intake. A comparison of eating alone and eating with others. Physiology \& Behavior, 88(4-5), 498-505. doi:10.1016/ j.physbeh.2006.04.025.

Higgs, S. (2008). Cognitive influences on food intake. The effects of manipulating memory for recent eating. Physiology \& Behavior, 94(5), 734-739. doi:10.1016/ j.physbeh.2008.04.012.

Higgs, S., \& Woodward, M. (2009). Television watching during lunch increases afternoon snack intake of young women. Appetite, 52(1), 39-43. doi:10.1016/ j.appet.2008.07.007.

Hogarth, L., Balleine, B. W., Corbit, L. H., \& Killcross, S. (2012). Associative learning mechanisms underpinning the transition from recreational drug use to addiction. Annals of the New York Academy of Sciences, 1-13. doi:10.1111/j.17496632.2012.06768.x.

Hogarth, L., Chase, H. W., \& Baess, K. (2012). Impaired goal-directed behavioural control in human impulsivity. Q. J. Exp. Psychol. (Hove)., 65, 305-316.

Hogarth, L., Chase, H. W., \& Baess, K. (2012). Impaired goal-directed behavioural control in human impulsivity. The Quarterly Journal of Experimental Psychology.

Horstmann, A., Busse, F. P., Mathar, D., Müller, K., Lepsien, J., Schlögl, H., et al. (2011). Obesity-related differences between women and men in brain structure and goal-directed behavior. Frontiers in Human Neuroscience, 5(58), 58. doi:10.3389/fnhum.2011.00058.

Killgore, W. D. S., \& Yurgelun-Todd, D. A. (2005). Body mass predicts orbitofrontal activity during visual presentations of high-calorie foods. Neuroreport, 16(8), 859-863.

Le, D. S. N. T., Pannacciulli, N., Chen, K., Del Parigi, A., Salbe, A. D., Reiman, E. M., et al (2006). Less activation of the left dorsolateral prefrontal cortex in response to a meal. A feature of obesity. The American Journal of Clinical Nutrition, 84(4), 725-731.

Morewedge, C. K., Huh, Y. E., \& Vosgerau, J. (2010). Thought for food. Imagined consumption reduces actual consumption. Science (New York, N.Y.), 330(6010), 1530-1533. doi:10.1126/science.1195701.

Murray, E. A., \& Rudebeck, P. H. (2013). The drive to strive. Goal generation based on current needs. Frontiers in Neuroscience, 7, 112. doi:10.3389/fnins.2013.00112.

Nader, M. A., Morgan, D., Gage, H. D., Nader, S. H., Calhoun, T. L., Buchheimer, N. et al. (2006). PET imaging of dopamine D2 receptors during chronic cocaine self-administration in monkeys. Nature Neuroscience, 9(8), 1050-1056. doi:10.1038/nn1737.

Nederkoorn, C., Braet, C., Van Eijs, Y., Tanghe, A., \& Jansen, A. (2006). Why obese children cannot resist food. The role of impulsivity. Eating Behaviors, 7(4), 315-322. doi:10.1016/j.eatbeh.2005.11.005.

Nederkoorn, C., Smulders, F. T. Y., Havermans, R. C., Roefs, A., \& Jansen, A. (2006). Impulsivity in obese women. Appetite, 47(2), 253-256. doi:10.1016 j.appet.2006.05.008.

Nijs, I. M. T., \& Franken, I. H. A. (2012). Attentional processing of food cues in overweight and obese individuals. Current Obesity Reports, 1(2), 106113.

Nummenmaa, L., Hirvonen, J., Hannukainen, J. C., Immonen, H., Lindroos, M. M., Salminen, P., et al. (2012). Dorsal striatum and its limbic connectivity mediate abnormal anticipatory reward processing in obesity. PLOS ONE, 7(2), e31089. doi:10.1371/journal.pone.0031089.

Pannacciulli, N., Del Parigi, A., Chen, K., Le, S. N. T., Reiman, E. M., \& Tataranni, P. A. (2006). Brain abnormalities in human obesity. A voxel-based morphometric study. Insulin, 31, 1419-1425. doi:10.1016/j.neuroimage.2006.01.047.

Pignatti, R., Bertella, L., Albani, G., Mauro, A., Molinari, E., \& Semenza, C. (2006) Decision-making in obesity. A study using the Gambling Task. Eating and Weight Disorders: EWD, 11(3), 126-132.

Rasmussen, E. B., Lawyer, S. R., \& Reilly, W. (2010). Percent body fat is related to delay and probability discounting for food in humans. Behavioural Processes, 83(1) 23-30. doi:10.1016/j.beproc.2009.09.001.

Robinson, T. E., \& Berridge, K. C. (1993). The neural basis of drug craving: an incentive-sensitization theory of addiction. Brain Research. Brain Research Reviews, 18, 247-291.

Rolls, B. J., Rolls, E. T., Rowe, E. A., \& Sweeney, K. (1981). Sensory specific satiety in man. Physiology \&' Behavior, 27(1), 137-142.

Rothemund, Y., Preuschhof, C., Bohner, G., Bauknecht, H.-C., Klingebiel, R., Flor, H. et al. (2007). Differential activation of the dorsal striatum by high-calorie visual food stimuli in obese individuals. Neuroimage, 37(2), 410-421. doi:10.1016/ j.neuroimage.2007.05.008

Schwabe, L. \& Wolf, O. T. (2011). Stress-induced modulation of instrumental behavior From goal-directed to habitual control of action. Behavioural Brain Research, 219(2), 321-328. doi:10.1016/j.bbr.2010.12.038

Small, D. M., Jones-Gotman, M., \& Dagher, A. (2003). Feeding-induced dopamine release in dorsal striatum correlates with meal pleasantness ratings in healthy human volunteers. Neuroimage, 19(4), 1709-1715. doi:10.1016/S10538119(03)00253-2.

Snoek, H. M., Huntjens, L., Van Gemert, L. J., De Graaf, C., \& Weenen, H. (2004). Sensory-specific satiety in obese and normal-weight women. The American Journal of Clinical Nutrition, 80(4), 823-831.

Stoeckel, L. E., Cox, J. E., Cook, E. W., \& Weller, R. E. (2007). Motivational state modulates the hedonic value of food images differently in men and women. Appetite, 48(2), 139-144. doi:10.1016/j.appet.2006.07.079.

Stoeckel, L. E., Weller, R. E., Cook, E. W., Twieg, D. B., Knowlton, R. C., \& Cox, J. E. (2008). Widespread reward-system activation in obese women in response to pictures of high-calorie foods. Neuroimage, 41(2), 636-647. doi:10.1016 j.neuroimage.2008.02.031

Temple, J. L., Giacomelli, A. M., Kent, K. M., Roemmich, J. N., \& Epstein, L. H. (2007). Television watching increases motivated responding for food and energy intake in children. American Journal of Clinical Nutrition, 85, 355-361.

Thanos, P. K., Michaelides, M., Benveniste, H., Wang, G. J., \& Volkow, N. D. (2007) Effects of chronic oral methylphenidate on cocaine self-administration and striatal dopamine D2 receptors in rodents. Pharmacology, Biochemistry, and Behavior, 87(4), 426-433. doi:10.1016/j.pbb.2007.05.020.

Vartanian, L. R., Sokol, N., Herman, C. P., \& Polivy, J. (2013). Social models provide a norm of appropriate food intake for young women. PLOS ONE, 8(11), e79268. doi:10.1371/journal.pone.0079268.

Verdejo-García, A., Lawrence, A. J., \& Clark, L. (2008). Impulsivity as a vulnerability marker for substance-use disorders. Review of findings from high-risk research, problem gamblers and genetic association studies. Neuroscience and Biobehavioral Reviews, 32(4), 777-810. doi:10.1016/j.neubiorev.2007.11.003.

Volkow, N. D., Wang, G.-J., Fowler, J. S., \& Telang, F. (2008). Overlapping neuronal circuits in addiction and obesity. Evidence of systems pathology. Philosophical Transactions of the Royal Society of London. Series B, Biological Sciences, 363(1507), 3191-3200. doi:10.1098/rstb.2008.0107.

Volkow, N. D., Wang, G.-J., Tomasi, D., \& Baler, R. D. (2013). Obesity and addiction. Neurobiological overlaps. Obesity Reviews: An Official Journal of the International 
Association for the Study of Obesity, 14(1), 2-18. doi:10.1111/j.1467789X.2012.01031.x.

Wang, G. J., Volkow, N. D., Logan, J., Pappas, N. R., Wong, C. T., Zhu, W., et al. (2001). Brain dopamine and obesity. Lancet, 357(9253), 354-357.

Wansink, B. (2004). Environmental factors that increase the food intake and consumption volume of unknowing consumers. Annual Review of Nutrition, 24(217), 455-479. doi:10.1146/annurev.nutr.24.012003.132140.

Weingarten, H. P., \& Elston, D. (1990). The phenomenology of food cravings. Appetite, 15(3), 231-246.

Weller, R. E., Cook, E. W., Avsar, K. B., \& Cox, J. E. (2008). Obese women show greater delay discounting than healthy-weight women. Appetite, 51(3), 563-569. doi:10.1016/j.appet.2008.04.010.

Weygandt, M., Mai, K., Dommes, E., Leupelt, V., Hackmack, K., Kahnt, T., et al. (2013). The role of neural impulse control mechanisms for dietary success in obesity. Neuroimage, 83C, 669-678. doi:10.1016/j.neuroimage.2013.07 028 .

\section{Uncited references}

De Wit, S., \& Dickinson, A. (2009). Associative theories of goal-directed behaviour A case for animal-human translational models. Psychological Research, 73(4), 463-476. doi:10.1007/s00426-009-0230-6.

Kishinevsky, F. I., Cox, J. E., Murdaugh, D. L., Stoeckel, L. E., Cook, E. W., \& Weller, R. E. (2012). fMRI reactivity on a delay discounting task predicts weight gain in obese women. Appetite, 58(2), 582-592. doi:10.1016/j.appet.2011.11 .029 . 